\title{
Ethnologies
}

\section{A decade of implementation of the Convention for the Safeguarding of the Intangible Cultural Heritage Challenges and perspectives}

\section{Cécile Duvelle}

Volume 36, numéro 1-2, 2014

Patrimoine culturel immatériel

Intangible Cultural Heritage

URI : https://id.erudit.org/iderudit/1037598ar

DOI : https://doi.org/10.7202/1037598ar

Aller au sommaire du numéro

Éditeur(s)

Association Canadienne d'Ethnologie et de Folklore

ISSN

1481-5974 (imprimé)

1708-0401 (numérique)

Découvrir la revue

Citer cet article

Duvelle, C. (2014). A decade of implementation of the Convention for the Safeguarding of the Intangible Cultural Heritage: Challenges and perspectives. Ethnologies, 36(1-2), 27-46. https://doi.org/10.7202/1037598ar

\section{Résumé de l'article}

Dans cet article, Cécile Duvelle expose les principaux points de l'évaluation de la Convention pour la sauvegarde du patrimoine culturel immatériel entreprise par l'UNESCO dix ans après qu'elle ait été adoptée, en 2003. Elle présente les réussites de la Convention et les écueils auxquels elle s'est heurtée. À partir des données d'une enquête auprès des États signataires ainsi que de nombreuses parties prenantes non gouvernementales telles que des OGN, des représentants d'organisations de porteurs du PCI et des universitaires, les auteurs du rapport d'évaluation considèrent que cette Convention de 2003 constitue un outil juridique extrêmement pertinent au niveau international en ce qu'elle concorde avec les priorités nationales et locales et avec les besoins des communautés, des groupes et des individus concernés. La Convention a élargi la conception traditionnelle du patrimoine pour inclure des points de vue anthropologiques et sociologiques. Elle a également introduit un certain nombre d'importants concepts relatifs au PCI, comme le fait que la communauté soit la réelle détentrice du patrimoine et que ce patrimoine se définit dans les termes de la communauté ; que la notion de culture est vivante et évolue en se transmettant d'une génération à l'autre ; et que le concept de sauvegarde constitue une mesure visant à assurer la viabilité du PCI. La Convention a introduit une nouvelle terminologie et de nouvelles définitions qui ont depuis gagné une place de premier plan au niveau mondial et supplanté d'anciens concepts. Cet article discute en profondeur des avantages et des inconvénients de l'inscription d'éléments du PCI sur les listes, des promesses et des insuffisances de la participation communautaire, et des difficultés que posent les questions de propriété intellectuelle et de diversité culturelle dans le domaine du PCI, de la nécessaire collaboration des administrations des différentes conventions sur le patrimoine de l'UNESCO et de la façon dont le patrimoine culturel immatériel peut contribuer au développement durable, à la résolution de conflits et aux droits humains. L'auteur conclut en commentant les recommandations du rapport d'évaluation.
Ce document est protégé par la loi sur le droit d'auteur. L'utilisation des services d’Érudit (y compris la reproduction) est assujettie à sa politique d'utilisation que vous pouvez consulter en ligne.

https://apropos.erudit.org/fr/usagers/politique-dutilisation/ 


\section{A DeCADE OF IMPLEMENTATION OF THE CONVENTION FOR THE SAFEgUARDING OF THE INTANGIBLE CUlTural HeRITAGe \\ Challenges and perspectives ${ }^{1}$}

\section{Cécile Duvelle \\ UNESCO}

The Convention for the Safeguarding of the Intangible Cultural Heritage looked resolutely forward when it was adopted in 2003. Built upon almost sixty years of concern by UNESCO with protection of heritage in general, it resulted from three decades of reflection on living traditions in particular. Today, it counts 161 States Parties, large and small, from every region of the world. Its rate of ratification has been more rapid than that of any of the other UNESCO cultural conventions. ${ }^{2}$ Ten years after its adoption, including seven years of actual implementation at the international level, what did it achieve, and how can we imagine its future?

1. This presentation is based on the documentation produced by the UNESCO Intangible Cultural Section for the Conference held in Chengdu, China, 14-16 June 2013, on the occasion of the tenth anniversary of the 2003 Convention (http://www.unesco. org/culture/ich/index.php?pg=00015\&categ=2013), as well as on the Evaluation of UNESCO's Standard setting Work of the Culture Sector, Part I - 2003 Convention for the Safeguarding of the Intangible Cultural Heritage (Internal Oversight Service, IOS/EVS/PI/129, October 2013). http://www.unesco.org/culture/ich/doc/src/IOS-EVSPI-129_REV.-EN.pdf

2. Already in its sixth year, the 2003 Convention exceeded the number of ratifications of the 1970 Convention on the Means of Prohibiting and Preventing the Illicit Import, Export and Transfer of Ownership of Cultural Property (http://www.unesco. org/new/en/culture/themes/illicit-traffic-of-cultural-property/1970-convention/) during more than 40 years, and in less than a decade it received as many ratifications as during 25 years for the 1972 Convention concerning the Protection of the World Cultural and Natural Heritage (http://whc.unesco.org/). 


\section{Achievements of the Convention: changing the discourse of $\mathrm{ICH}$ and implanting new concepts}

A recent evaluation of the 2003 Convention for the Safeguarding of the Intangible Cultural Heritage found that States Parties as well as many non-state stakeholders involved in the implementation of the Convention, including NGOs, representatives of intangible cultural heritage (ICH) bearer organisations, and academics "consider the 2003 Convention for the Safeguarding of the Intangible Cultural Heritage to be a highly relevant international legal instrument, both in terms of its consistency with national and local priorities and with the needs of the concerned communities, groups and individuals".

It further notes that "the 2003 Convention has significantly broadened the international discourse around the definition and meaning of cultural heritage. The concept of $\mathrm{ICH}$ itself is quite new and its use has largely been credited to the 2003 Convention. As recently as ten years ago the term ICH was almost unknown and was only used by a small group of experts. Intangible Cultural Heritage is today recognized as a valuable and integral part of people's cultural heritage. The Convention broadened the more traditional view of heritage to include anthropological and sociological points of view. It also introduced a number of important concepts related to $\mathrm{ICH}$, such as the understanding that the community is the real bearer of ICH and that this heritage is defined in terms of the community; the notion that culture is living and evolving as it is transmitted from one generation to another; and the concept of safeguarding as measures aimed at ensuring the viability of ICH".

It is true that foremost among its greatest achievements must be the degree to which it has transformed global understandings of intangible cultural heritage and its safeguarding. Even if intangible cultural heritage itself is as old as humanity, and its safeguarding has been the subject of deliberate attention from practitioners and, for several centuries already, from scholars and cultural workers, the Convention introduced new terminology and definitions that have since gained global prominence, supplanting older concepts.

During the preparation of the Convention, experts discussed the meaning and understanding of key terms in order to create an internationally viable vocabulary for the Convention. As a parallel to this exercise, a profoundly new understanding of the nature of intangible cultural heritage emerged, requiring, for many people, a fundamentally 
different way of thinking and acting than had previously prevailed. This was often particularly true for experts and researchers who had devoted their lives to studying intangible cultural heritage, only to discover that in the Convention's conceptions, they no longer retained an undisputed hegemony over what that heritage was or what should be done with it.

\section{Listing: predicted pitfalls?}

The first Bolivian proposals of 1973 concerning international measures for the "protection of the folk arts and cultural heritage of the various nations of the world" already called for the establishment of an "International Register of Folkloristic Cultural Property". Through the three decades of study and discussion that resulted in the 2003 Convention, the advantages and disadvantages of different systems of registering, cataloguing, listing and inventorying were debated at length. Grounded both in the preceding centuries of folklorists' efforts to collect and catalogue the expressions of oral heritage and in the model of listing that was established under the 1972 Convention, the impulse to create an international system of registration was a powerful one, despite numerous cautions and critiques that were expressed along the way. Looking back, one would like to ask, which advantages of international listing stood out compellingly enough to override the predicted pitfalls? And what are the advantages of listing seen from today's perspective?

Here again, the evaluation has given interesting perspectives on this issue: "While the Representative List has contributed to increasing the visibility of the Convention and to raising awareness about intangible cultural heritage, its relative importance is overrated. Other mechanisms, such as the List of Intangible Cultural Heritage in Need of Urgent Safeguarding, the Register of Best Safeguarding Practices and the International Assistance are underused". The evaluation concludes that "a better balance needs to be found between these mechanisms by (a) clarifying all misperceptions regarding the concepts and intention of the Representative List; (b) promoting and re-positioning the Urgent Safeguarding List; (c) promoting the International Assistance Programme; and (d) rethinking the way best practices are identified and disseminated".

Indeed, the Urgent Safeguarding List's aim is to encourage the safeguarding of ICH elements "whose viability is at risk" (criterion U.2.a. of the Operational Directives) or "facing grave threats as a result of which it cannot be expected to survive without immediate safeguarding" 
(criterion U.2.b of the Operational Directives). While it therefore had initially intended to serve as the most important international safeguarding mechanism of the 2003 Convention, overall the list remains underused. ${ }^{3}$

While the evaluation found that the purpose of the Urgent Safeguarding List seems to be clear to most stakeholders, it is often perceived as the public demonstration of a failure rather than a commitment to safeguarding. The analogy made with the List of World Heritage in Danger set up under the 1972 Convention is also part of the confusion. Moreover, the resources needed to implement the safeguarding measures proposed in the nomination may constitute an obstacle. But the availability of financial resources under the Fund of the Convention, largely underutilized despite devoted in priority to support safeguarding efforts for elements inscribed on the Urgent Safeguarding List, seem to contradict this hypothesis.

And the introduction of a global limit to the number of nomination files processed by year, with priority given the submitting States with no or fewer inscriptions so far and Urgent Safeguarding List nominations, does not seem to have changed this trend.

The nomination process itself has nevertheless in some cases promoted ownership of safeguarding plans among both practitioners and communities. In several countries the inscription of elements on the Urgent Safeguarding List has also effectively contributed to their safeguarding and even to the wider goals of the 2003 Convention. For example, the inscription of "Ojkanje singing" by Croatia in 2010 has led to support from various levels of Government for its safeguarding through promotion, documentation and research. It has also changed the wider public attitude towards this element and motivated tradition bearers and younger generations to engage in its active transmission. In Viet Nam, the inscription of "Ca trù singing" and "Xoan singing of Phú Tho Province" elements on the Urgent Safeguarding List drew attention from politicians, tradition-bearers and the public throughout the country. As the result, financial, human and other resources have been invested by the Government, NGOs and individuals for the safeguarding of these elements.

But the Representative List is doubtless the most visible and popular of the mechanisms set up by the 2003 Convention so far. The evaluation established that the Representative List has indeed enhanced the visibility and raised awareness of ICH (which is the objective of the List). Survey

3. So far, 106 such nominations have been submitted for the Urgent Safeguarding List (with 35 elements inscribed), to be compared with the 685 submitted to the Representative List and the 191 elements inscribed. 
results and interviews during the evaluation process show that in some countries, inscription has led to intergenerational dialogue by motivating tradition bearers to find ways of transmission of $\mathrm{ICH}$ to younger generations (such as in Croatia). It has also increased interest among youth, such as for example in Georgia, where there is growing interest in polyphonic singing. In Nigeria the same can be said of the Ijele masquerade where youth sing and dance to Akunechenyi music. In India, the inscription of "Kutiyattam, Sanskrit theatre" created awareness of this practice and a Training Centre was opened in Kerala. As a result, more young people are now studying the practice. Stakeholders also reported about how the process of developing nominations to the Representative List itself has in many cases led to intercultural and even interreligious dialogue, such as, for instance, in Serbia. In many countries, the preparation of a nomination file has resulted in increased dialogue among communities and between communities and Government.

Interviews have also shown, however, that many State Parties misunderstand the purpose of the Representative List. Some believe that inscription of an element creates national ownership of that element for the submitting State Party. In several instances this has generated competition and conflict between States Parties and even a rush to submit a file for nomination. The lack of dialogue between States Parties about these issues is seen as one of the reasons for the inappropriate use of the Representative List and has become a cause for concern. Moreover, the important notion of 'representativeness' that underpins this list (as 'outstanding value' does for the World Heritage List) and that represents the contribution of ICH to cultural diversity worldwide is not always understood by States Parties.

To be inscribed on the Representative List, an element should satisfy the five criteria stipulated in the Operational Guidelines (I.2). However, the evaluation found that this was not always the case. "In several instances, elements were inscribed on the List by the Intergovernmental Committee against the recommendations of the Subsidiary Body. The fact that the Body and the Intergovernmental Committee were using different criteria has led many to question the credibility of the List and compare it with lists of other conventions that are becoming more and more politicized ".

For example, one of the key criteria for the Representative List is that safeguarding measures are elaborated that may protect and promote the element (criterion 3), though this often seems to be regarded as secondary in nature. The evaluation found that large numbers of nomination files do not provide satisfactory information on measures to safeguard the elements 
proposed for inscription. Indeed, many stakeholders interviewed and surveyed for this evaluation (and confirmed by participants in the Chengdu Conference) have expressed concern over the fact that the importance of inscription is overemphasised, and that safeguarding itself is not seen as much of a priority.

Many States Parties have indeed been in a rush to inscribe a maximum number of elements on the Representative List, which has caused it to swell up since 2009. The attention to the Representative List has also led to each Intergovernmental Committee session spending the majority of its time examining nominations to this List alone, consequently leaving very little time for other matters. The result of all this is seen by many stakeholders as quite unfortunate: listing becoming an end in itself rather than a tool that encourages safeguarding.

Another important criterion of the Representative List concerns community involvement in the nomination of an element (criterion 4). The evaluation found that in some countries, communities are indeed the ones who initiate the preparation of the nomination files, while in others the process remains very much top-down and is Government led. A number of NGOs have even expressed concerns over the fact that there is no way for the Intergovernmental Committee to check if communities have really been consulted. This uncertainty and lack of real monitoring is also obvious in the Periodic Reporting process.

When these conclusions have been presented to the Committee by the Director of the Internal Oversight Service in Baku, some members felt uncomfortable with the stigmatization the evaluation put on the Representative List compared to the Urgent Safeguarding List. The decision proposed called upon "States Parties and the General Assembly, as well as the Secretariat, category 2 centres, non-governmental organizations and all other stakeholders to: a) Promote the Urgent Safeguarding List by re-positioning it as an expression of States Parties' commitment to safeguarding and to the implementation of the Convention, and especially recognize those States Parties that submit nominations to the Urgent Safeguarding List; and b) Clarify all misconceptions regarding the purpose and use of the Representative List"; and the Committee was invited to "decide to ensure that inscription of elements to the Representative List reflect more closely the criteria and procedures specified in Chapter I.2 of the Convention's Operational Directives". The draft decision was not accepted as such, and was amended by the Committee to read: "a) Promote the Urgent Safeguarding List by re-positioning it as an expression 
of States Parties' commitment to safeguarding and to the implementation of the Convention, and promote international assistance as a tool for the safeguarding of intangible cultural heritage and the implementation of the Convention; and b) Respect and promote the purposes and best use of the Representative List" as well as "Ensure that inscription of elements to all lists reflects closely the criteria and procedures specified in Chapter I of the Convention's Operational Directives". The debate on this issue will continue in November next in Paris (9.COM).

Moreover, the evaluation noted, although community participation is at the heart of the 2003 Convention, it has proven to be one of the most challenging aspects in its implementation. Community participation needs to be enhanced in many areas related to the implementation of the Convention, including in inventorying, in the elaboration of safeguarding programmes and projects, and in the preparation of nomination files. No topic has indeed received greater attention from the Committee and its bodies than that of the widest possible participation of communities, groups and, where appropriate, individuals in safeguarding intangible cultural heritage, as required by Article 15 of the Convention, and in the nomination and inscription process specifically, as required by the Operational Directives. The question of communities and their effective participation in safeguarding their own intangible cultural heritage is one that pervades every aspect of the nomination and inscription process and their participation thus needs to be demonstrated throughout every section of the nomination: "the communities, groups and, where appropriate, individuals concerned are essential participants at all stages of the identification and inventorying of intangible cultural heritage, the preparation and submission of nominations, the promotion of visibility of intangible cultural heritage and awareness of its significance, as well as the implementation of safeguarding measures, and [it] calls upon submitting States to demonstrate their participation in the nomination process through ample and convincing evidence". ${ }^{4}$ Where a nomination does not demonstrate that sufficient attention had been paid to such participation, the Committee has been unable to inscribe the element. ${ }^{5}$

\section{Parallel universes: intellectual property, world heritage and cultural goods and services}

During the first decade of life of the 2003 Convention for the Safeguarding of the Intangible Cultural Heritage, developments continued

4. Decision 8.COM 8; cf. Decision 7.COM 7, Decision 6.COM 7, Decision 5.COM 13.

5. See, for instance, Decision 8.COM 7.a.11. 
simultaneously in three adjacent spheres of international cooperation: a) efforts spearheaded by the World Intellectual Property Organization (WIPO) ${ }^{6}$ to accord protection to traditional knowledge, genetic resources and traditional cultural expressions based on intellectual property principles, b) on-going implementation on a global scale of the 1972 Convention concerning the Protection of the World Cultural and Natural Heritage ${ }^{7}$, and c) the adoption and entry into force of the 2005 Convention on the Protection and Promotion of the Diversity of Cultural Expressions ${ }^{8}$. Even if the four may sometimes seem to inhabit separate and parallel universes, there are in fact a number of convergences among them and many reciprocal effects of one on another.

Developing an intellectual property regime for traditional knowledge, genetic resources and traditional cultural expressions

Questions concerning intellectual property rights had an important part in UNESCO's discussions on conservation of culture since the early 1950s. In 1973, when the Bolivian authorities proposed to the Director-General ${ }^{9}$ that the Intergovernmental Copyright Committee consider the question of establishing an "international instrument for the protection of folklore", the measures they advocated for consideration included some that now fall within the safeguarding scope of the 2003 Convention (e.g. 'preservation, promotion and diffusion') and others that focussed on protecting folklore expressions as intellectual property in their conception at the time, seen as the property of the State. As these two approaches were increasingly in subsequent years considered to require distinct responses, the question of intellectual property protection was taken on by WIPO, and the 2003 Convention specifically excludes intellectual property from its scope.

Established in 2000, WIPO's Intergovernmental Committee on Intellectual Property and Genetic Resources, Traditional Knowledge and Folklore (IGC) $)^{10}$ has since been debating provisions that could figure into one or more international legal instruments aiming to ensure effective protection of those three closely related but distinct domains. From the beginning, the difficulty arose of how an international intellectual property system that had evolved over centuries aiming to protect the unique

6. http://www.wipo.int/tk/en/

7. http://whc.unesco.org/

8. http://www.unesco.org/new/en/culture/themes/cultural-diversity/diversity-ofcultural-expressions/the-convention/

9. http://unesdoc.unesco.org/images/0000/000058/005845eb.pdf

10. http://www.wipo.int/tk/en/igc/ 
creative expressions of known persons could embrace dynamic cultural expressions that have ancient roots but are created and recreated by communities and groups and regarded as collectively 'owned'. Very soon, the WIPO negotiations focused on sui generis (special) provisions, based on intellectual property principles but which are adapted to respond to the particular features of traditional cultural expressions. Within its current draft provisions, the IGC refers to "indigenous peoples and communities and traditional and other cultural communities and their members", although each of these terms is contested and - as with the 2003 Convention - there may never be a strict definition of 'communities'. Elsewhere, reference is made to 'indigenous [peoples] and local communities', with the brackets indicating lack of full consensus on the terminology.

The question of value also figures centrally into the work of the WIPO IGC. The clearest expression of its thinking comes in the set of draft 'objectives' that introduce the current set of provisions on traditional cultural expressions (WIPO/GRTKF/IC/25/411), in which it is stated that "The protection of traditional cultural expressions should aim to [...] recognize that indigenous peoples and communities and traditional and other cultural communities consider their cultural heritage to have intrinsic value, including social, cultural, spiritual, economic, scientific, intellectual, commercial and educational values". ${ }^{12}$ Although these objectives are still at a 'first draft' stage, and have not yet been negotiated, they clearly place the emphasis on the communities' own valuation of their heritage and its importance to them. The larger debate rests on the question of how best to ensure on the one hand that the communities' values are not violated through misuse, and on the other hand that when value is added through dissemination or other use, they are the ones who benefit.

WIPO's intergovernmental negotiations had already anticipated many of the concerns with the rights of indigenous peoples that were finally enunciated in the 2007 United Nations Declaration on the Rights of Indigenous Peoples ${ }^{13}$, but it, more so than the pre-existing UNESCO Conventions, has since 2007 fully integrated the principles set out there,

11. http://www.wipo.int/edocs/mdocs/tk/en/wipo_grtkf_ic_25/wipo_grtkf_ic_25_4. doc

12. These principles were presented to the eighth session of the IGC in 2005 and have since been labelled with the notation, 'to be discussed at a later stage' (WIPO/ GRTKF/IC/25/4); in the case of protection of traditional knowledge, the latest revision of the provisions sets 'economic' and 'commercial' in brackets, indicating that there are divergent views on whether they should be retained or deleted.

13. http://www.un.org/esa/socdev/unpfii/documents/DRIPS_en.pdf 
particularly in Article 31: "Indigenous peoples have the right to maintain, control, protect and develop their cultural heritage, traditional knowledge and traditional cultural expressions, as well as the manifestations of their sciences, technologies and cultures, including human and genetic resources, seeds, medicines, knowledge of the properties of fauna and flora, oral traditions, literatures, designs, sports and traditional games and visual and performing arts. They also have the right to maintain, control, protect and develop their intellectual property over such cultural heritage, traditional knowledge, and traditional cultural expressions". Comprehensive integration of the Declaration remains a challenge facing the three UNESCO Conventions.

\section{Bringing local values and local communities into World Heritage}

The 1972 Convention concerning the Protection of the World Cultural and Natural Heritage ${ }^{14}$ has continued to thrive during the first decade of the 2003 Convention, attaining almost universal ratification by the States of the world. Cultural and natural heritage protected by the 1972 Convention is limited to properties that meet the threshold of Outstanding Universal Value and are suitable to meet one or more of the criteria specified in the Convention's Operational Guidelines. Inherent in this language when it was adopted was the conception that "parts of the cultural or natural heritage are of outstanding interest and therefore need to be preserved as part of the world heritage [...] as a whole" (Preamble), and that such value is determined not by the communities residing in or making use of a site, but by an external process of assessing its uniqueness and relevance within a global context.

In 1994, the World Heritage Committee launched the Global Strategy for a Representative, Balanced and Credible World Heritage List. As explained in the report of an expert group at the time, the Committee was called 'to take into account all the possibilities for extending and enriching [the List] by means of new types of property whose value might become apparent as knowledge and ideas developed. The List should be receptive to the many and varied cultural manifestations of outstanding universal value through which cultures expressed themselves' (WHC-94/CONF.003/ INF. $\left.6^{15}\right)$. Over the following years - and even as the 2003 Convention was being drafted - the World Heritage Committee continued to debate a more inclusive World Heritage List and a more expansive interpretation of

14. http://whc.unesco.org/

15. http://whc.unesco.org/archive/global94.htm\#debut 
Outstanding Universal Value, as summarized in the 2003 conference and document, 'Linking Universal and Local Values: Managing a Sustainable Future for World Heritage' ${ }^{\prime 16}$ that served as a capstone to the Strategy's first decade.

This opening up continued in parallel with the adoption and entry into force of the 2003 Convention. Discussions within the Committee and the larger World Heritage community continued to focus on the fullest possible involvement of the communities residing in or near sites or utilizing them for diverse purposes. In 2007 the World Heritage Committee adopted its Decision $31 \mathrm{COM} 13 \mathrm{~A}^{17}$, 'recognizing the critical importance of involving indigenous, traditional and local communities in the implementation of the Convention' and deciding 'to add "communities" as a fifth strategic objective' to complement credibility, conservation, capacity building and communication that had been adopted in 2002 (Decision 26 COM 17.18).

As communities became recognized as pivotal in the management and conservation of World Heritage sites, their issues and concerns also began to take various positions closer to centre stage. This trajectory was widely referred to within the framework of the $40^{\text {th }}$ anniversary of the 1972 Convention in 2012, focussing on the theme 'World Heritage and Sustainable Development: the Role of Local Communities'. Finally, and as a result of the discussions throughout the year of celebrations, the Kyoto Vision ${ }^{19}$ encouraged the international community to strive to ensure effective involvement of local communities, indigenous peoples, experts and youth in all aspects of World Heritage conservation.

\section{Promoting the diversity of cultural expressions}

The third parallel domain of action is the subject of the 2005 Convention on the Protection and Promotion of the Diversity of Cultural Expressions $^{20}$. That Convention is concerned with promoting favourable conditions for cultures to flourish and to interact and for cultural creativity to thrive, particularly through policies and measures that recognize 'the distinctive nature of cultural activities, goods and services as vehicles of identity, values and meaning' (Article 1). The Convention is careful to

16. http://whc.unesco.org/en/series/13/

17. http://whc.unesco.org/en/documents/9192

18. http://whc.unesco.org/en/decisions/814/

19. http://whc.unesco.org/uploads/news/documents/news-953-1.doc

20. http://www.unesco.org/new/en/culture/themes/cultural-diversity/diversity-ofcultural-expressions/the-convention/ 
distinguish the social and cultural value of such expressions and activities from their commercial value, in that regard finding common ground with WIPO's enumeration of 'social, cultural, spiritual, economic, scientific, intellectual, commercial and educational values' (see above). Yet the 2005 Convention, as an instrument of sustainable development, also seeks to ensure that the creators of cultural expressions can benefit effectively and equitably when cultural activities, goods and services enter the stream of commerce.

Where the 2003 Convention speaks of 'communities, groups and, in some cases, individuals', the 2005 Convention speaks in mirror image of 'individuals, groups and societies' (Article 4.3), emphasizing the role of 'artists and others involved in the creation of cultural expressions' (Article $6.2(\mathrm{~g}))$. The closest counterpart to the 2003 Convention's 'communities' are what the 2005 Convention refers to as 'social groups', who are seen together with individuals - as entitled to 'create, produce, disseminate, distribute and have access to their own cultural expressions' and to have access to diverse cultural expressions other than their own (Article 7). The emphasis here is then on the value that individuals and groups attach to cultural expressions - whether their own or those of others - but neither on a notion of universal or outstanding value, as in the 1972 Convention, nor on one that gives primacy to the value that communities assign to their own heritage (even while respecting the heritage of others), as in the 2003 Convention. (The 2003 Convention notably balances the goal of ensuring access to cultural expressions with that of respecting customary practices governing such access, thereby finding common ground with the WIPO efforts to protect secret or sacred knowledge.)

Particularly in its preamble, the 2005 Convention evokes values that are shared with the 2003 Convention and with WIPO's efforts concerning traditional knowledge and traditional cultural expressions and points to the common engagement of all three to promote sustainable development. It thus takes into account the "importance of the vitality of cultures, including for persons belonging to minorities and indigenous peoples, as manifested in their freedom to create, disseminate and distribute their traditional cultural expressions and to have access thereto, so as to benefit them for their own development" (Preamble). One can indeed imagine countless examples of cultural expressions that fall simultaneously within the ambit of WIPO, the 2005 Convention and the 2003 Convention and the 1972 Convention, even if each of them would approach a given expression from different perspectives and with different, albeit complementary, objectives in mind. 
In the decade since the Convention for the Safeguarding of the Intangible Cultural Heritage was adopted by the UNESCO General Conference on 17 October 2003, each of the four has continued its evolution and pursued its mission, even while necessarily being influenced - in greater or lesser degree - by the others. States Parties to one or several Conventions, as well as Member States of WIPO, balance their sometimes complementary and sometimes contrasting scopes and purposes, integrating each of them into national legislation and policy frameworks and bringing their experience with one to bear on their implementation of the other. Whether the coming decades see more frequent convergences or fewer rests in the hands of those States.

The evaluation itself found that the 2003 Convention is closely linked to the 1972 and 2005 conventions as well as to some of the work of the World Intellectual Property Organization. But it also noted that while this is generally acknowledged by stakeholders, possibilities for strengthening policy and implementation connections, exchanging experiences and enhancing cooperation between the various culture conventions, and between UNESCO and WIPO, have not been fully exploited.

It is in this context that the Committee recognized "the need to create opportunities for joint thinking, exchange of experiences, cooperation and synergies between UNESCO's culture conventions of 1972, 2003 and 2005 and establish appropriate mechanisms for this"; and invited "the respective Intergovernmental Committees of the 1972 and 2005 Conventions to join efforts to that end", requesting the Secretariat to facilitate such cooperation and promote the establishment of such mechanisms. ${ }^{21}$

\section{Open questions and future directions}

The 2003 Convention for the Safeguarding of the Intangible Cultural Heritage is strengthened by a shared understanding among the States and the many bearers and practitioners that the importance of intangible cultural heritage does not lie in any given cultural expression or manifestation per se but rather in the wealth of knowledge, skills and values it encompasses. Transmission and sustainability, identity and community participation are central attributes and fundamental values of intangible heritage that powerfully infuse a myriad of knowledge systems, rich with meaning, vibrant in their transmission and essential for human development.

21. Decision 8.COM 5.c.1. 
The accumulated knowledge embodied and expressed in the intangible cultural heritage is invaluable to those who depend on these knowledge systems in their daily lives. It is so not only because it relates directly to their modes of living and provides them with a sense of identity and continuity, but also because it is often the only source of knowledge they have access to when deprived of access to global education and information systems. Intangible cultural heritage, as a living and adaptive corpus of knowledge, is by nature sustainable, energetic and dynamic, guided by humanism and by a deep respect for the environment and ecological systems. It constitutes a community manual that can successfully be referred to by new initiatives such as the 'green economy', by societies in their shift towards climateresilient agriculture, and by communities in their efforts to create more inclusive and equitable societies.

\section{Intangible cultural heritage in sustainable development}

In May 2013 in Hangzhou, China, the Hangzhou Declaration, 'Placing Culture at the Heart of Sustainable Development Policies ${ }^{22}$, was adopted. This declaration will inform the consultations leading to the setting of the post-2015 agenda and the inclusion of culture within new Sustainable Development Goals. It is against this renewed international effort and conviction that the future of the 2003 Convention may be considered.

We now have on our shelves a growing number of cases and studies concerning the application - at local and sub-regional levels - of intangible cultural heritage as a means for communities and societies to strive for sustainable human development. Many of these intangible cultural heritage practices and expressions are intertwined with the questions that arise about the future of the 2003 Convention.

To begin with one example: inequalities plague communities today, both among and within countries. In Peru, the national average for years of schooling among young adults is just under ten years whereas for poor, indigenous women the figure is five years; in China in 2005 the percentage of underweight children in the richer eastern provinces (5.8\%) was less than half that of the poorer western provinces (12.5\%); in Viet Nam in 2006, only $7 \%$ of ethnic minority households had access to improved sanitation, while the rate was $43 \%$ for majority households (from 'Equity, Inequality and Human Development in a Post-2015 Framework ${ }^{23}$, UNDP Human

22. http://www.unesco.org/new/fileadmin/MULTIMEDIA/HQ/CLT/images/ FinalHangzhouDeclaration20130517.pdf

23. http://hdr.undp.org/en/media/Equity\%20Inequality $\% 20 \mathrm{Human} \% 20$ 
Development Report Office Research Paper, February 2013). As the wave of 'Occupy' movements and 'Indignant' movements that swept the globe in 2011 and 2012 demonstrates, social and economic inequalities are a pressing concern in upper-income countries as well, as people everywhere seek to improve their well-being and enhance their human development.

Fortunately, intangible cultural heritage is not like other resources that are inequitably distributed through facts or accidents of history, climate or geography, and whose unequal distribution thus creates and reinforces other inequalities in a perpetual vicious circle. Intangible heritage is, by contrast, a universal resource and thus all the more valuable when and where other resources may be lacking. Hence the profound link between equitable human development and the potential of intangible cultural heritage to transform development outcomes. To do so successfully and in many different contexts requires new methodological tools, and imposes the question: How can the close relation between intangible cultural heritage and sustainable development be more effectively highlighted and strengthened in the future?

"Transforming development requires that all citizens feel vested in the broader goals of society, showing respect and compassion for others and a commitment to building social cohesion"; so stated the Human Development Report 2013, 'The Rise of the South: Human Progress in a Diverse World ${ }^{24}$ ' (UNDP 2013). This requires that States and citizens understand that human development is about more than just enhancing individual capabilities, since these capabilities are embedded in broader social systems whose health requires enhanced social competencies.

Even so, what is still missing is a shared recognition that development programmes and strategies should integrate intangible cultural heritage and the knowledge systems in which it is embedded within their goals, indicators and targets. Without such actions, and the provision of related guidance on human capacity building, the potential of intangible cultural heritage to contribute to sustainable development risks being largely untapped. The integration of intangible heritage is also a key requirement when it comes to designing and implementing effective development initiatives, and bridges must be built between intangible heritage communities and specialists, on the one hand, and sectors as diverse as forests, fisheries, health, education, water and sanitation and rural development on the other hand, even if these latter are sometimes thought of as having little to do with culture or

Development\%20in\%20post-2015\%20framework.pdf

24. http://hdr.undp.org/en/reports/global/hdr2013/download 
heritage. When such inter-disciplinary activity is encouraged, experience shows that effective and equitable outcomes are more likely to result.

\section{Climate change mitigation}

Climate change and other global environmental threats will increasingly become serious barriers to further human development. Humans are transforming the Earth's life support system - the atmosphere, oceans, waterways, forests, ice sheets and biodiversity that allow us to thrive and prosper - in ways that undermine development gains. Within countries, different demographic groups (such as urban or rural, or strata distinguished by income) contribute differently to national $\mathrm{CO}_{2}$ emissions and also bear differential burdens of climate change.

Thus, while national income and human development indexes may rise (which helps indicate a progression out of poverty), $\mathrm{CO}_{2}$ emissions also usually rise (which indicates the growing unsustainability in the current patterns of consumption and use of resources such as energy). The impacts of a steady rise in per capita emissions of $\mathrm{CO}_{2}$ will be differently experienced by intangible cultural heritage bearers and practitioners. For those living outside of industrialized and urbanized settlements, their contribution to $\mathrm{CO}_{2}$ and greenhouse gases is usually marginal. Yet their intangible cultural heritage often embodies modes of living that can guide planners looking for practical methods to reduce per capita emissions for a region or province, including for urban and industrial zones.

At the same time, intangible heritage is rich with examples of community-based natural resource management systems in which access to resources is equitably shared and competing needs mediated. Climate change necessarily means that certain resources that are adequate or even plentiful today will not be so in the future, and as resources diminish, the possibility of conflict over them increases.

\section{Conflict avoidance and peace making, and disaster prevention and recovery}

UNESCO promotes the use of science and technology to contribute to both disaster risk reduction and conflict resolution. Recent events testify to the role of culture and heritage, and particularly of intangible cultural heritage, in restoring social balance and rebuilding community cohesion in post-disaster and post-conflict situations: the Haiti earthquake, the floods in Pakistan, the socio-political transitions in the Middle East and North 
Africa region, and emergency actions in Mali.

The recognition that these events are representative of a larger number of similar events and conditions elsewhere has been reflected in the post2015 agenda: "At least one-fifth of humanity lives in countries experiencing significant violence, political conflict, insecurity and societal fragility. Such conditions form a major obstacle to development, with lasting implications for societal well-being. No country affected by violence or fragility has achieved a single MDG target". ('Realizing the Future We Want for All', the UN System Task Team on the Post-2015 UN Development Agenda.)

While many conflicts are related to issues of sharing natural resources, in particular fresh water resources, a multi-disciplinary approach that is synchronous with UNESCO's role in the field of disaster preparedness and mitigation brings intangible cultural heritage to the fore. Found at the locus of community institutions, education, science and communication, intangible cultural heritage allows communities, States and all actors to pursue culturally relevant pathways towards conflict resolution and reconciliation.

Developments in international human rights, particularly those of indigenous peoples

Human social systems and communities - the practitioners and bearers of intangible cultural heritage and knowledge systems - are directly affected by climate and ecosystem changes. The degradation of any one of these erodes the community's sense of identity and may interrupt the transmission of traditions, practices and knowledge. Hence there are multiple connections across these sectors - most of which are invisible when viewed through a lens that pursues only economic growth. Moreover, the decisions that people make daily can influence a cascade of events that affect community, household and individual vulnerability and/or resilience to climate change.

Most indigenous peoples are situated in areas where the vast majority of the world's genetic resources are found. Many have cultivated and used biological diversity in a sustainable way for thousands of years. Some of their practices have been proven to enhance and promote biodiversity at the local level and aid in maintaining healthy ecosystems, and that is why the contribution of indigenous and local communities to the conservation and sustainable use of biological diversity goes far beyond their role as natural resource managers. The recognition of their intangible cultural heritage as 
a set of time-tested methodologies employed to steward their landscapes for centuries indicates the complementary nature of intangible cultural heritage safeguarding and the strengthening of human rights.

Worldwide, distinctive communities have organized themselves around shared disabilities and created vibrant intangible heritage expressing their community identity. In other cases, persons with disabilities have long had specific roles and responsibilities with respect to the intangible heritage of larger communities, for example blind minstrels or musicians in many parts of the world. A powerful new tool for recognizing the rights of persons with disabilities, the Convention on the Rights of Persons with Disabilities ${ }^{25}$, entered into force 24 months after the 2003 Convention, but there is yet to be formal cooperation between them.

\section{Gender equality and gender diversity}

The relationship between intangible cultural heritage and gender becomes increasingly germane as the implementation of the 2003 Convention generates a number of safeguarding measures and plans that provide opportunities for dialogue on intangible cultural heritage and gender, notably at the community level. The elaboration of gender-specific roles in intangible cultural heritage brings to the fore perspectives that can be applied with respect for local gender conceptions and for cultural and other human rights.

Prominent amongst these concerns is the importance of gender in the practice and transmission of intangible cultural heritage (how specific expressions of intangible heritage depend on gender-specific practices and transmission), conceptions of gender and the differences they represent in various practices of intangible heritage, the recognition and encouragement of female and male transmitters of intangible heritage and the resulting empowerment of women and men. Particularly when mainstreamed from the beginning within educational strategies, cultural initiatives that recognise gender diversity within a human rights-based approach may play a particularly important role in building confidence and tolerance among multicultural communities and in providing a common space for dialogue. On this topic, the evaluation noted that "many stakeholders acknowledge the gender dimension of ICH. However, an in-depth debate about gender equality and ICH has not yet happened. Given the absence of such a debate and any appropriate guidance, the working mechanisms of the Convention, related documents, forms and assessments, as well as the support provided

25. http://www.un.org/disabilities/convention/conventionfull.shtml 
by the Secretariat have been quite gender blind so far. The same applies to the Periodic Reports. This is a lost opportunity to create awareness about this very important topic and to collect interesting information and good practices that could later be shared with others". The evaluation therefore recommended to revise all relevant documents and forms (including the Operational Guidelines, the Periodic Reporting Formats, and nomination files) to include gender-specific guidance and questions. A work in progress.

\section{Conclusion}

The most promising conclusions of the evaluation of the 2003 Convention for the Safeguarding of the Intangible Cultural Heritage are certainly those addressing its future challenges:

While many State Parties have integrated the Convention's provisions in cultural policies and laws following ratification, a lot more work needs to be done to establish the required legislative and policy environment, both as it relates to laws and policies in the field of culture, as well as to those in the field of sustainable development that have a bearing on the implementation of the 2003 Convention. This is one of the areas where support is needed and where UNESCO could intervene more explicitly.

Overall, the Convention lacks a Theory of Change and an overall results framework with objectives, time-frames, indicators and benchmarks, which makes it difficult to capture and demonstrate results. Periodic reports provide a valuable source of information on the implementation of the Convention. However, for the purpose of monitoring the implementation of the Convention globally, the Reports alone currently do not provide all the required information. The reporting format should be revised and the Reports complemented by other sources, so that a more complete data set on results achieved and lessons earned can be established.

In many countries Government institutions lack the financial and human resources to successfully implement the Convention. Understanding the concepts of the Convention also often remains a challenge, both at the government and community levels. This is especially evident when it comes to inventorying, the design and implementation of safeguarding measures, cooperation with other State Parties, preparation of nomination files (both national and multi-national), and community consultation and participation in all of these areas.

UNESCO has put in place an extensive world-wide capacity building programme with a network of qualified experts. Of all the mechanisms 
established by the Convention and the Secretariat to support the implementation of the Convention, the capacity building programme is considered by many to be the most important. The programme could usefully be extended to include more support in policy and legislative development; ICH and sustainable development and the required intersectoral cooperation; community mobilization and participation; and $\mathrm{ICH}$ and gender equality in a context of human rights. More efforts are needed for follow-up and assessment of results achieved by the capacity building activities.

NGOs are acknowledged to play an important role in the implementation of the Convention at the national level. Their contribution is primarily focused on the implementation of safe-guarding measures. Other important roles, such as contributing to cultural policy making or mediating and building bridges between various actors, such as between communities and Government, are less recognized. At the international level, entry points for $\mathrm{NGOs,} \mathrm{including} \mathrm{organizations} \mathrm{representing} \mathrm{ICH}$ bearers, to contribute to decision making are limited. Many accredited NGOs feel that their accreditation status is not taken seriously by the Intergovernmental Committee as the NGO forum Statement and individual contributions of NGOs and other observers are often not sufficiently considered during the debates and therefore do not have much effect on decisions taken by the Intergovernmental Committee. One of the reasons for why NGOs' views are not taken into consideration by the Intergovernmental Committee seems to have to do with the accreditation criteria of NGOs, which are not stringent enough. This has led to the rapid approval of many organisations that are not playing a very active role in the implementation of the Convention.

Among the many recommendations of this evaluation, the latter is of utmost importance. The Intergovernmental Committee has invited all States Parties to the Convention to "Promote increased NGO and community involvement in the development of policy, legislation, safeguarding plans and sustainable development plans". In short, to address the community participation at all stages of the safeguarding process in a real and effective manner. The real success of the Convention will be assessed, in a few years, towards this expected result. 